\title{
miR-494 inhibits ovarian cancer cell proliferation and promotes apoptosis by targeting FGFR2
}

\author{
XIAOJUAN ZHAO, YUN ZHOU, YU CHEN and FENG YU \\ Department of Gynecology and Obstetrics, Nanjing Medical University Affiliated Wuxi Second Hospital, \\ Wuxi, Jiangsu 214000, P.R. China
}

Received February 11, 2015; Accepted March 2, 2016

DOI: $10.3892 / \mathrm{ol} .2016 .4527$

\begin{abstract}
MicroRNAs (miRs) have been reported to be key regulators in numerous types of cancer. The aim of the present study was to investigate the role of miR-494 in ovarian cancer. Expression of miR-494 was analyzed in ovarian cancer tissues and cell lines by reverse transcription-quantitative polymerase chain reaction (RT-qPCR). miR-494 mimic or negative control was transiently transfected into A2780 and SKOV 3 cell lines. A cell counting kit- 8 assay was performed to assess the effects of miR-494 on cell proliferation, and flow cytometry was used to evaluate the apoptotic rate. The target gene of miR-494 was detected by luciferase assay. Expression of fibroblast growth factor receptor 2 (FGFR2) was identified using RT-qPCR and western blotting. In the present study, decreased expression of miR-494 was observed in ovarian cancer samples and cell lines. Overexpression of miR-494 inhibited ovarian cancer cell proliferation by inducing apoptosis. Additional investigation indicated that FGFR2 was a direct target of miR-494. Taken together, the results of the present study suggested that miR-494 suppressed ovarian cancer cell proliferation by inducing apoptosis via targeting FGFR2.
\end{abstract}

\section{Introduction}

MicroRNAs (miRs) are small, non-coding RNAs that have significant roles in a number of biological processes (1). miRs are able to regulate the expression of a wide variety of genes by binding the 3'-untranslated region (UTR), suppressing messenger (m)RNA translation or degrading mRNA, thus modulating numerous cellular activities (2). Emerging evidence has demonstrated that a number of miRs act as tumor suppressor genes or oncogenes during tumor

Correspondence to: Dr Feng Yu, Department of Gynecology and Obstetrics, Nanjing Medical University Affiliated Wuxi Second Hospital, 68 Zhongshan Road, Wuxi, Jiangsu 214000, P.R. China E-mail: fy528935@163.com

Key words: microRNA-494, proliferation, apoptosis, fibroblast growth receptor 2 , ovarian cancer development, suggesting that they may be useful as novel diagnostic and therapeutic markers (1). Previous studies have demonstrated an abnormal miR expression profile in ovarian cancer, suggesting miRs may have a role in the development of ovarian cancer $(3,4)$.

Ovarian cancer is the primary cause of cancer-associated mortality in women, with an annual incidence of 238,719 and mortality rate of 151,917 individuals worldwide in 2012 (5). Due to a lack of efficient screening and early diagnosis, an abundance of patients present with distant metastases at the time of diagnosis; therefore, ovarian cancer is a challenging public health issue (6). The traditional treatments for ovarian cancer comprise a combination of surgery and chemotherapy (7); however, even following treatment, the prognosis of late-stage patients is poor (8). Therefore, it is crucial to investigate the molecular mechanisms of ovarian cancer in order to develop improved methods of diagnosis.

miR-494 is located on chromosome 14q32.31 (9). It has been observed that aberrant expression of miR-494 is involved in various stages of tumorigenesis (10). Overexpression of miR-494 promoted apoptosis and inhibited growth in gastrointestinal stromal tumor cells and esophageal squamous cell carcinoma cells (11). In A549 human lung cancer cells, miR-494 was reported to suppress cell proliferation and colony forming activity, and additionally induced senescence (12). miR-494 was observed to suppress the cell viability and angiogenic ability of medulloblastoma cells (13). By contrast, induced expression of miR-494 enhances cell migration and invasion in glioma cells by targeting p190B RhoGTPase activating protein (14). In human hepatocellular carcinoma, miR-494 is overexpressed and increases proliferation through an acceleration of G1/S transition by targeting the mutated in colorectal cancer tumor suppressor (15). However, to the best of our knowledge, little has been reported regarding the function of miR-494 in ovarian cancer.

In the present study, it was initially demonstrated that miR-494 is underexpressed in ovarian cancer samples and cell lines. Overexpression of miR-494 in ovarian cancer cell lines inhibited their proliferation and induced cell apoptosis. Furthermore, a luciferase reporter assay confirmed that fibroblast growth receptor 2 (FGFR2) was a target of miR-494, implying that miR-494 may suppress ovarian cancer cell proliferation via targeting of FGFR2. 


\section{Materials and methods}

Tissue specimens. A total of 25 pairs of ovarian cancer tissue and adjacent non-tumor tissue were collected at Nanjing Medical University Affiliated Wuxi Second Hospital (Wuxi, China) from patients during resection. Paired non-tumor tissues (adjacent to the tumor) were obtained from the same patient that the tumor tissue samples were collected, during the same procedure. The tissue samples were obtained during surgery and immediately frozen in liquid nitrogen until RNA extraction. The mean age of the patients was 51.5 years (range, 34.0-69.0 years). None of the patients had received radiation or chemotherapy prior to surgery. Written informed consent was obtained from all patients. The present study was approved by the Ethical Committee of Nanjing Medical University Affiliated Wuxi Second Hospital (Wuxi, China).

Cell culture and transfection. Ovarian cancer cell lines (ES2, HO8910, OVCAR3, A2780, SKOV3 and HeLa) were obtained from the Cell Bank of the Chinese Academy of Sciences (Shanghai, China). Cells were cultured in RPMI-1640 medium (Gibco; Thermo Fisher Scientific, Inc., Waltham, MA, USA), supplemented with $1 \%$ penicillin/streptomycin (Invitrogen; Thermo Fisher Scientific, Inc.) and $10 \%$ fetal bovine serum (GE Healthcare Life Sciences, Logan, UT, USA), at $37^{\circ} \mathrm{C}$ in a humidified atmosphere with $5 \% \mathrm{CO}_{2}$. miR-494 mimic and negative control oligonucleotide sequences were obtained from Shanghai GenePharma Co., Ltd., (Shanghai, China). The sequences of miR-494 mimic and negative control were as follows: miR-494 mimic forward, 5'-UGAAACAUACACGGG AAACCUC-3' and reverse, 5'-GGUUUCCCGUGUAUGUUU CAUU-3'; the negative control forward, 5'-UUCUCCGAA CGUGUCACGUTT-3' and reverse, ACGUGACACGUUCGG AGAATT-3'. A total of $2 \times 10^{5}$ cells were seeded into a six-well plate (Corning, Inc., Corning, NY, USA) and 100 nM miR-494 mimic and negative control were transiently transfected into cells using Lipofectamine ${ }^{\circledR} 2000$ (Invitrogen; Thermo Fisher Scientific, Inc.) once the cells had reached 70-90\% confluence, respectively.

Reverse transcription-quantitative polymerase chain reaction (RT-qPCR). Total RNA from the tissue samples and cell lines was extracted using TRIzol reagent (Invitrogen; Thermo Fisher Scientific, Inc.), according to the manufacturer's protocol. Reverse transcription was performed to obtain complementary DNA using a reverse transcription kit (PrimeScript ${ }^{\mathrm{TM}}$ RT reagent Kit with gDNA Eraser; Takara Bio, Inc., Otsu, Japan), which also contained DNase. Briefly, $1 \mu \mathrm{g}$ RNA, $2 \mu \mathrm{l}$ of $5 \mathrm{X}$ gDNA Eraser buffer and $1 \mu \mathrm{l}$ of gDNA Eraser and RNase Free $\mathrm{dH}_{2} \mathrm{O}$ were mixed and incubated at $42^{\circ} \mathrm{C}$ for 2 min to remove the DNA. The RT reaction system contained $10 \mu \mathrm{l}$ of the aformentioned reaction solution, $1 \mu \mathrm{l}$ of PrimeScript RT Enzyme Mix I, $1 \mu \mathrm{l}$ of RT Primer Mix, $4 \mu \mathrm{l}$ of 5 X PrimeScript Buffer 2 and $4 \mu \mathrm{l}$ of RNase Free $\mathrm{dH}_{2} \mathrm{O}$. The incubation conditions were $37^{\circ} \mathrm{C}$ for $15 \mathrm{~min}$, followed by $85^{\circ} \mathrm{C}$ for $5 \mathrm{sec}$. A sample with no DNA was used as the negative control. All reactions were performed with an ABI 7300 Real-Time PCR System (Applied Biosystems; Thermo Fisher Scientific, Inc.). The expression of miR-494 was analyzed by PCR using the SYBR ${ }^{\circledR}$ Premix Ex Taq $^{\text {TM }}$ II kit (Takara Bio, Inc.). U6 was used for normalization.
The primers were purchased from Guangzhou RiboBio Co., Ltd. (Guangzhou, China), and the sequences used were as follows: miR-494 forward, 5'-TGACCTGAAACATACACG GGA-3' and reverse, 5'-TATCGTTGTACTCCACTCCTT GAC-3'; U6 forward, 5'-AAAGACCTGTACGCCAACAC-3' and reverse, 5'-GTCATACTCCTGCTTGCTGAT-3'. The PCR cycling conditions were $95^{\circ} \mathrm{C}$ for $3 \mathrm{~min}$, followed by 40 cycles at $95^{\circ} \mathrm{C}$ for $30 \mathrm{sec}, 62^{\circ} \mathrm{C}$ for $30 \mathrm{sec}$ and $72^{\circ} \mathrm{C}$ for $30 \mathrm{sec}$.

The expression of FGFR2 was examined using a SYBR ${ }^{\circledR}$ Premix Ex Taq ${ }^{\mathrm{TM}}$ II kit (Takara Bio, Inc.). $\beta$-actin was used as the internal control. Experiments were repeated three times. The primer sequences were as follows (Genscript, Nanjing, China): FGFR2 forward, 5'-TGACATTAACCGTGTTCC TGAG-3' and reverse, 5'-TGGCGAGTCCAAAGTCTGCTA T-3'; $\beta$-actin forward, 5'-GACCTCTATGCCAACACAGT-3' and reverse, 5'-AGTACTTGCGCTCAGGAGGA-3'. The PCR cycling conditions were $94^{\circ} \mathrm{C}$ for $5 \mathrm{~min}$, followed by 32 cycles of $95^{\circ} \mathrm{C}$ for $30 \mathrm{sec}, 60^{\circ} \mathrm{C}$ for $30 \mathrm{sec}$ and $72^{\circ} \mathrm{C}$ for $45 \mathrm{sec}$. The relative expression levels were evaluated by the $2^{-\Delta \Delta \mathrm{Cq}}$ method (16).

Cell counting kit (CCK)- 8 assay. Cell proliferation was assessed by CCK-8 assay. Cells were seeded into 96-well plates (Corning, Inc.) and transfected with miR-494 mimic or negative control as described previously. A total of 24, 48, 72, 96 and $120 \mathrm{~h}$ subsequent to transfection, $10 \mu \mathrm{l} \mathrm{CCK}-8$ (Beyotime Institute of Biotechnology, Haimen, China) was added into $100 \mu \mathrm{l}$ medium. Following $2 \mathrm{~h}$ incubation with the diluted CCK-8 in RPMI-1640 medium (Gibco; Thermo Fisher Scientific, Inc.), the cells were lysed in radioimmunoprecipitation assay buffer and centrifuged at $13,000 \mathrm{x} \mathrm{g}$ for $10 \mathrm{~min}$ at $4^{\circ} \mathrm{C}$. The absorbance of the supernatants was measured at $450 \mathrm{~nm}$ on an imark microplate reader (Bio-Rad Laboratories, Inc., Hercules, CA, USA).

Apoptosis assay using flow cytometry. Cell apoptosis was analyzed using a propidium iodide (PI)/Annexin V-fluorescein isothiocyanate (FITC) double staining cell apoptosis detection kit (KeyGEN BioTECH, Nanjing, China), according to the manufacturer's protocol, on a FACSCalibur ${ }^{\mathrm{TM}}$ (BD Biosciences, Franklin Lakes, NJ, USA). A total of 3x10 5 cells were seeded into a 6-well plate (Corning, Inc.) and transfected with miR-494 mimic or negative control. A total of $48 \mathrm{~h}$ later, cells were collected and stained with Annexin V-FITC/PI, and the percentage of apoptotic and viable cells was determined by flow cytometry.

Dual luciferase assay. The wild-type and mutant 3'-UTRs of FGFR2 were synthesized and cloned into the luciferase reporter vector pGL3 (catalog no., E1761; Promega Corp., Madison, WI, USA). HeLa cells were seeded into 24-well plates (Corning, Inc.) and cultured until they reached $70 \%$ confluence. Subsequently, 100 ng wild-type or mutant pGL3-FGFR2-3'-UTR and $10 \mathrm{ng}$ pRL-TK plasmid (E2241, Promega Corp.), together with $30 \mathrm{nM}$ miR-494 mimic or negative control were cotransfected into cells using Lipofectamine 2000. The Renilla luciferase activity was analyzed at $48 \mathrm{~h}$ post transfection using the Dual-Luciferase ${ }^{\circledR}$ Reporter Assay System (Promega Corp.) on a Lumat ${ }^{3}$ LB 9508 Single Tube Luminometer (Berthold Technologies GmbH \& Co. KG, Bad Wildbad, Germany). 
A

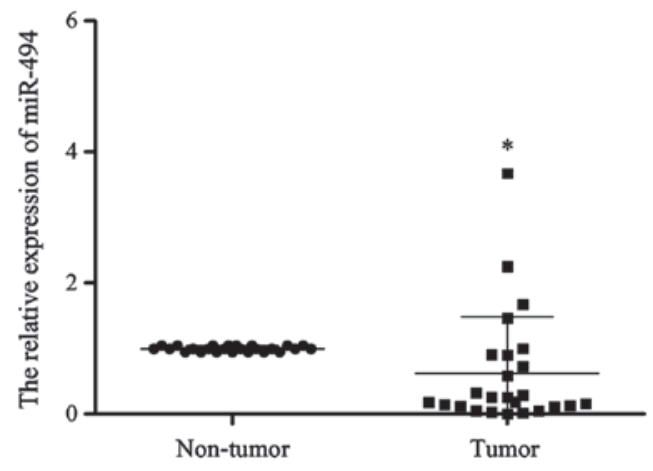



Figure 1. Expression of miR-494 is downregulated in ovarian cancer tissues and cell lines. (A) The expression of miR-494 was downregulated in ovarian cancer tissues. (B) The expression of miR-494 was downregulated in ovarian cancer cell lines compared with normal ovarian tissues. The graph shows the relative expression of miR-494 using the $2^{-\Delta \Delta \mathrm{Cq}}$ method, with U6 as the internal control. Data are presented as the mean \pm standard deviation from three independent experiments. ${ }^{*} \mathrm{P}<0.05$, compared with the Non-tumor group. miR, microRNA.

Renilla luciferase activity was normalized to firefly luciferase activity to control for transfection efficiency.

Western blot analysis. Following transfection, cells were washed twice with ice-cold phosphate-buffered saline, harvested using trypsin (Gibco; Thermo Fisher Scientific, Inc.) and lysed in radioimmunoprecipitation assay buffer (Beyotime Institute of Biotechnology). Following $30 \mathrm{~min}$ of incubation, the lysed cells were centrifuged at $13,000 \mathrm{x}$ g for $10 \mathrm{~min}$ at $4^{\circ} \mathrm{C}$, and the supernatant was removed and frozen at $-80^{\circ} \mathrm{C}$. Total protein extracted was quantified with a BCA Protein Assay kit (Beyotime Institute of Biotechnology). Equal amounts of protein $(80 \mu \mathrm{g})$ were separated by $10 \%$ sodium dodecyl sulfate polyacrylamide gel electrophoresis. The following primary antibodies were used: FGFR2 (dilution, 1:500; rabbit monoclonal; catalog no., \#11835; Cell Signaling Technology, Inc., Beverly, MA, USA) and $\beta$-actin (dilution, 1:1,000; rabbit polyclonal; catalog no., BA0410; Wuhan Boster Biological Technology, Ltd., Wuhan, China). Following incubation with the primary antibodies overnight at $4^{\circ} \mathrm{C}$, the membranes were washed with TBST and incubated with secondary antibody (dilution, 1:2,000; goat anti-rabbit; catalog no., BA1054; Wuhan Boster Biological Technology, Ltd.) at room temperature for $2 \mathrm{~h}$. Protein bands were detected using an enhanced chemiluminescence detection system (Beyotime Institute of Biotechnology).

Statistical analysis. The independent Student's t-test was used to compare two preselected groups, which were expressed as the mean \pm standard deviation. All statistical analyses were performed using SPSS version 17.0 (SPSS, Inc., Chicago, IL, USA). $\mathrm{P}<0.05$ was considered to indicate a statistically significant difference.

\section{Results}

Expression level of miR-494 in ovarian cancer tissues and cell lines. In order to investigate the potential role of miR-494 in the development of ovarian cancer, the present study detected the expression level of miR-494 in 25 ovarian cancer tissues and 5 cell lines (ES2, HO8910, OVCAR3, A2780, SKOV3) by RT-qPCR. The level of miR-494 expression in tumor tissues was reduced compared with that in normal ovary tissues $(\mathrm{P}=0.012$; Fig. 1A). Similarly, compared with the three normal ovarian tissues that were pooled and used as the normal control, the expression of miR-494 in the 5 ovarian cancer cell lines was reduced at different extent (A2780 vs. Non-tumor, $\mathrm{P}=0.017$; HO8910 vs. Non-tumor, $\mathrm{P}=0.089$; OVCAR3 vs. Non-tumor, $\mathrm{P}=0.28$; ES2 vs. Non-tumor, $\mathrm{P}=0.057$; SKOV3 vs. Non-tumor, $\mathrm{P}=0.015$; Fig. 1B). Taken together, these results suggest that miR-494 may be involved in the development of human ovarian cancer.

Overexpression of miR-494 inhibits ovarian cancer cell growth and promotes apoptosis. To investigate the role of miR-494 on cell growth and apoptosis, the present study performed a gain-of-function analysis using A2780 and SKOV3 cell lines. miR-494 mimic or negative control was transiently transfected into the two cell lines, and RT-qPCR was performed to confirm the effect $48 \mathrm{~h}$ later. As demonstrated in Fig. 2A and $\mathrm{B}$, the expression of miR-494 in A2780 [miR-494 vs. negative control (NC), $\mathrm{P}=0.019$ ] and SKOV3 (miR-494 vs. NC, $\mathrm{P}=0.021)$ cells was significantly increased following transfection. CCK-8 was performed to detect the growth ability of cells. The results of this assay indicated that overexpression of miR-494 resulted in a significant decrease in cell proliferation in $120 \mathrm{~h}$ (Fig. 3A, miR-494 mimic vs. NC, $\mathrm{P}=0.011$; Fig. 3B, miR-494 mimic vs. NC, $\mathrm{P}=0.038$ ). The present study additionally examined the apoptotic changes following miR-494 transfection with miR-949 mimic. The results revealed that the apoptotic rate in miR-494-transfected cells was increased compared with the control (Fig. 3C, miR-494 vs. NC, $\mathrm{P}=0.017$; Fig. 3D, miR-494 vs. NC, $\mathrm{P}=0.024)$.Taken together, these data suggest that miR-494 may inhibit ovarian cancer cell growth by inducing apoptosis.

FGFR2 is a target gene of miR-494. According to the predictions made by the online software TargetScan (www. targetscan.org), Pictar (pictar.mdc-berlin.de/) and miRanda (www.microrna.org), a large number of genes were identified as 
A

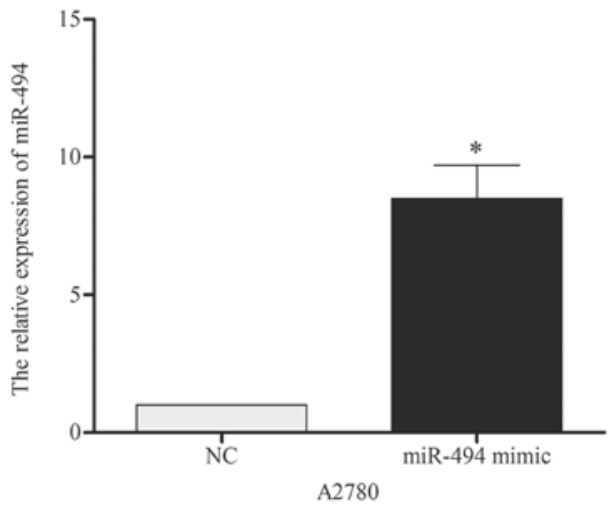

B

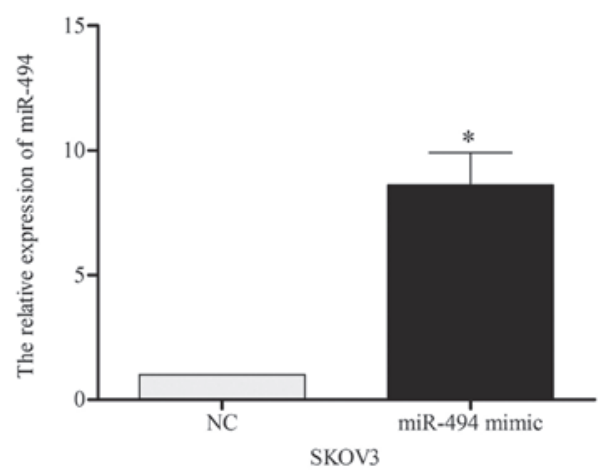

Figure 2. Levels of miR-494 in miR-494-transfected ovarian cancer cells. Transfection of miR-494 effectively elevated the expression of miR-494 in (A) A2780 and (B) SKOV3 cells. Data are presented as the mean \pm standard deviation from three independent experiments. " $\mathrm{P}<0.05$, compared with the NC group. miR, microRNA; NC, negative control.

A

A2780
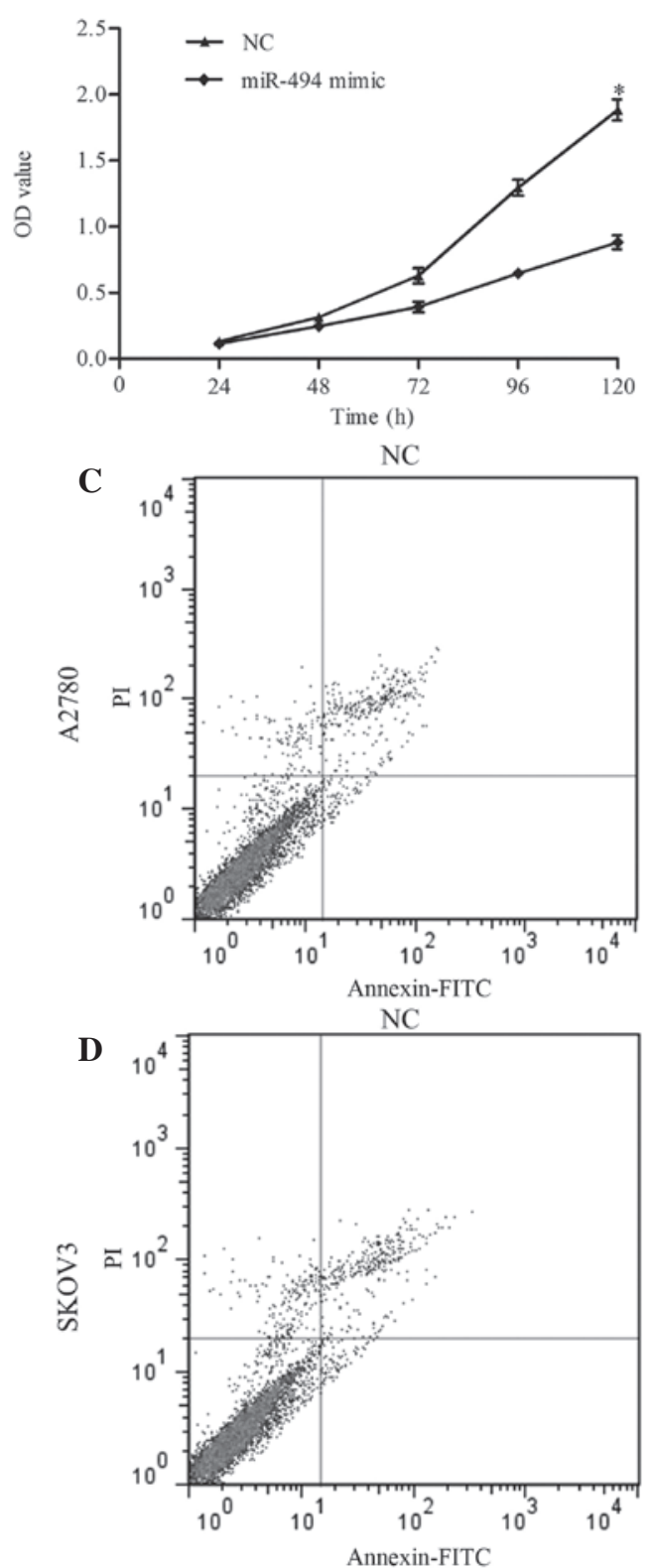

B
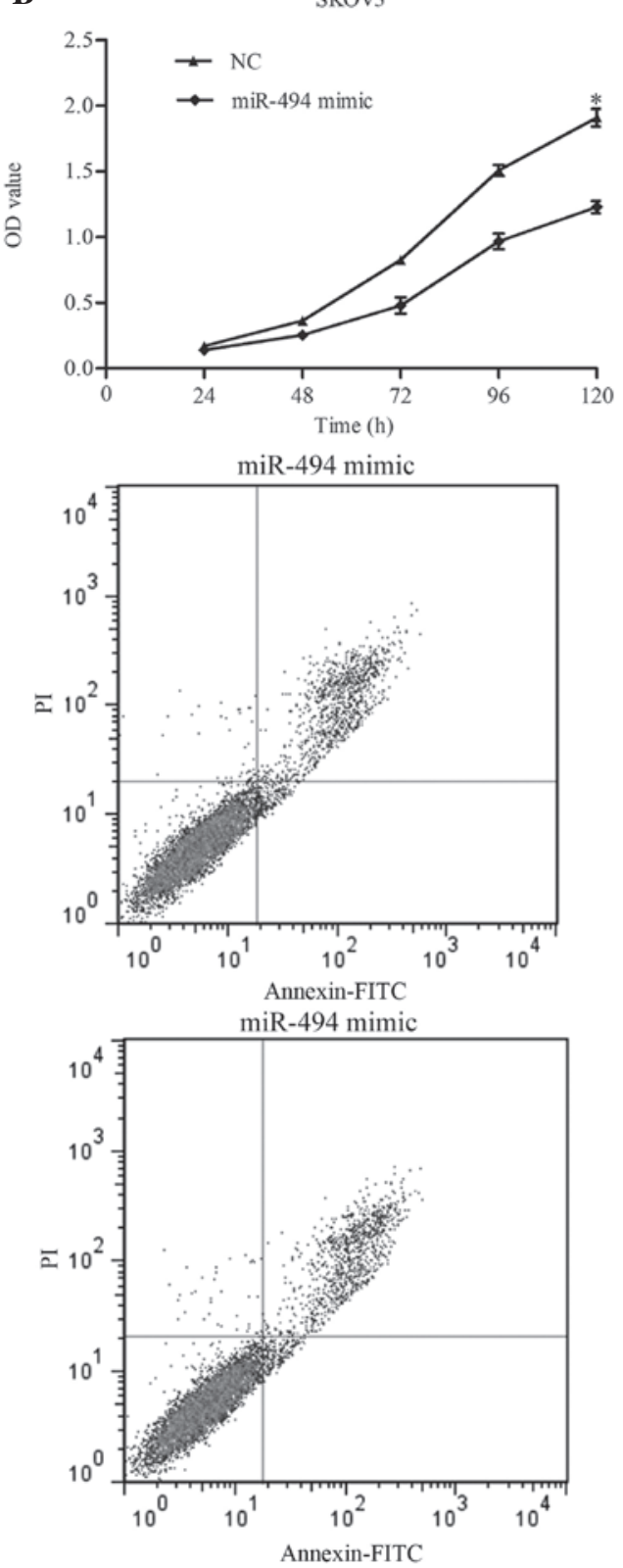

Figure 3. Effects of miR-494 on cell proliferation and apoptosis. Overexpression of miR-494 suppressed cell proliferation in (A) A2780 and (B) SKOV3 cells, measured by cell counting kit-8 assay. Overexpression of miR-494 enhanced cell apoptosis in (C) A2780 and (D) SKOV3 cells, measured by flow cytometry. Data are presented as the mean \pm standard deviation from three independent experiments. " $\mathrm{P}<0.05$, compared with the NC group. miR; microRNA; NC, negative control; OD, optical density; PI, propidium iodide; FITC, fluorescein isothiocyanate. 
A

WT 5' AUACUGACAAUAAAAAUGUUUCU 3 miR-494 $3^{\prime}$ CUCCAAAGGGCACAUACAAAGU 5

Mut $5^{\prime}$ AUACUGACAAUAAAAAACAAAgU 3

C

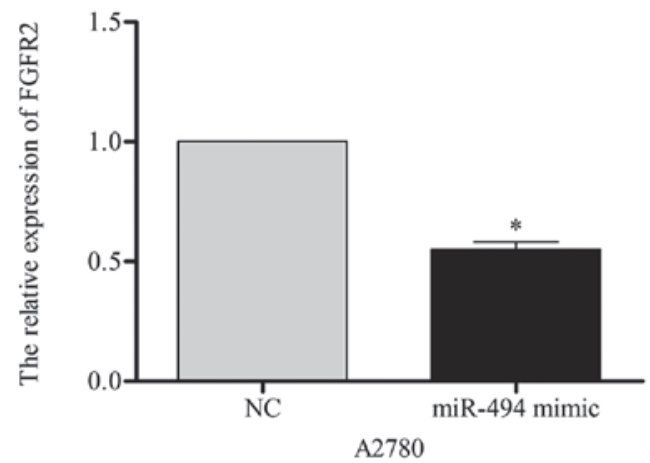

D



A2780
B
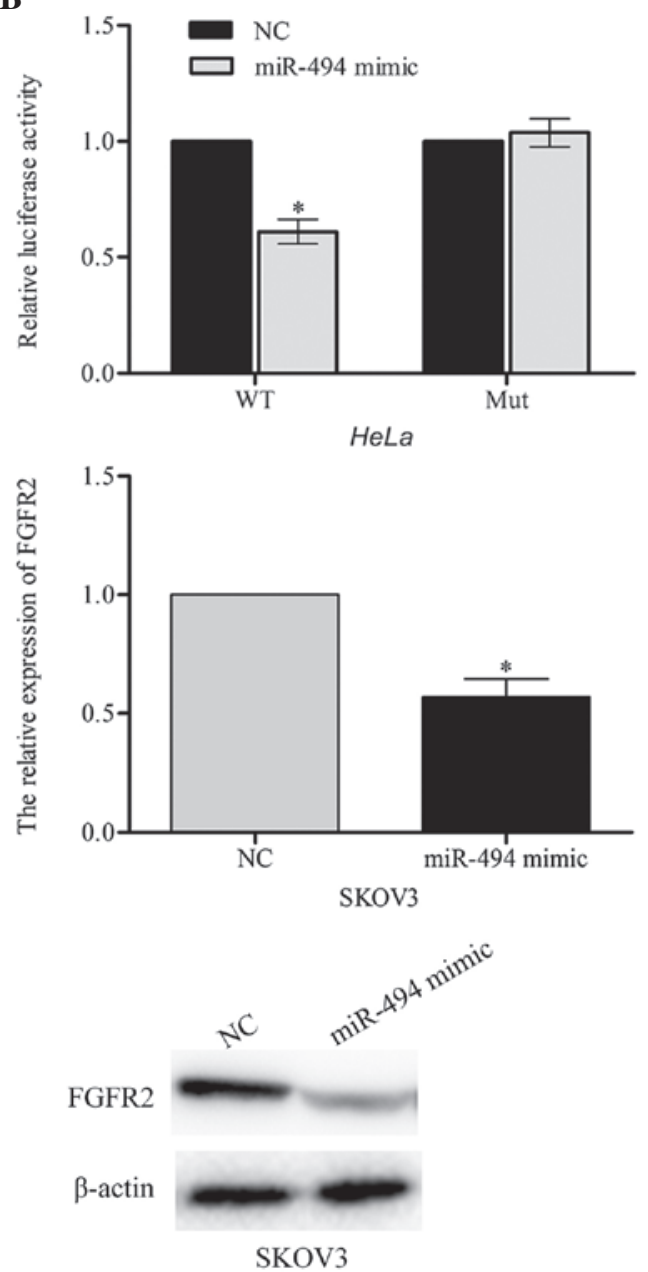

Figure 4. FGFR2 is a target of miR-494. (A) The binding sequence of miR-494 in FGFR2. (B) The relative luciferase activity was significantly decreased in cells cotransfected with miR-494 mimic and wild-type FGFR2 3'-UTR in HeLa cell lines. miR-494 inhibited the expression of endogenous FGFR2, observed in terms of (C) messenger RNA and (D) protein levels. $\beta$-actin was used as an internal control. Data are presented as the mean \pm standard deviation from three independent experiments. "P<0.05, compared with the (B) WT and (C) NC groups. FGFR2, fibroblast growth receptor 2; miR, microRNA; WT, wild-type; Mut, mutant, NC, negative control; UTR, untranslated region.

direct targets of miR-494. The present study selected FGFR2 as a likely regulator of cell apoptosis. A luciferase reporter assay was performed in order to investigate whether FGFR2 was a target for miR-494. The wild-type (pGL3-FGFR2-WT) and mutant (pGL3-FGFR2-Mut) binding site sequences of miR-494 are listed in Fig. 4A. The results of this assay demonstrated that the luciferase activity of pGL3-FGFR2-WT in the two cell lines was markedly reduced compared with the mutant pGL3-FGFR2-Mut (miR-494 mimic vs. NC, $\mathrm{P}=0.043$; Fig. 4B), which suggested that miR-494 may directly target FGFR2.

In order to confirm the endogenous regulatory role of miR-494 in relation to FGFR2 in ovarian cancer cells, the present study measured the level of FGFR2 in A2780 and SKOV3 cells following transfection with miR-494 mimic or negative control. The results of this investigation indicated that the FGFR2 mRNA and protein level were significantly downregulated in A2780 (miR-494 mimic vs. NC, $\mathrm{P}=0.031$ ) and SKOV3 (miR-494 mimic vs. NC, $\mathrm{P}=0.037$ ) cells that had been transfected with miR-494 mimic (Fig. 4C and D). Taken together, these results indicate that FGFR2 may be a direct target of miR-494.

\section{Discussion}

Due to the changes to the human lifestyle, the occurrence of reproductive-, diet- and hormone-associated types of cancer is increasing (17). Accumulating evidence has revealed that miRs participate in tumorigenesis, tumor development, drug resistance and other pathological processes of cancer (18). miRs affect malignant cellular behaviors by silencing a multitude of target genes, and regulating the downstream signaling pathways (19). By targeting various genes, miR may have opposing roles in different types of cancer (20). Similarly, miR-494 demonstrates contrasting functions in various types of cancer. In gastrointestinal stromal tumor cells, lung cancer cells (12), medulloblastoma cells (21), oral cancer cells (22), esophageal squamous cell carcinoma cells (23), gastric cancer (24) and cholangiocarcinoma (21), miR-494 functions as a tumor suppressor gene. By contrast, in glioma cells, oral squamous cell carcinoma (25), bronchial cancer (26) and hepatocellular carcinoma (15), miR-494 functions as an oncogene. In the present study, the expression profile of miR-494 was evaluated in 25 pairs of tumor and adjacent non-tumor samples. The results of this investigation revealed that the expression of 
miR-494 was reduced in cancer tissues compared with normal tissues, and that the five ovarian cancer cell lines exhibited a decreased miR-494 expression level compared with the normal control. These results are consistent with previous studies in ovarian cancer tissues and cell lines $(27,28)$, suggesting that miR-494 may have a significant role in ovarian cancer.

To elucidate the role and potential underlying mechanism of miR-494 in ovarian cancer, a gain-of-function study was performed on the A2780 and SKOV3 cell lines. The results of the present study indicated that miR-494 inhibited ovarian cancer cell proliferation and promoted cell apoptosis. Previous studies have shown that miR-494 participates in the regulation of cell apoptosis in human glioblastoma cells, non-small cell lung cancer and esophageal squamous cell carcinoma by targeting various genes $(23,29,30)$. Wang et al (31) reported that miR-494 was able to target pro-apoptotic and anti-apoptotic proteins, resulting in cardioprotective effects against ischemia/reperfusion-induced injury. To additionally investigate the pro-apoptotic role of miR-494 in ovarian cancer, the present study predicted the target gene of miR-494. It was confirmed by dual luciferase assay that FGFR2 was a target gene of miR-494. Subsequently, western blotting revealed that the mRNA and protein expression levels of FGFR2 were reduced in miR-494 overexpression A2780 and SKOV3 cell lines compared with control cells. This indicated that miR-494 may directly target FGFR2.

FGFR2 belongs to the FGFR family, and is comprised of 2 isoforms: FGFR2-IIIb and FGFR2-IIIc (32). FGFRs are transmembrane tyrosine kinase receptor proteins, which have crucial roles in embryonic development, cell growth, tumorigenesis, invasiveness, motility and angiogenesis by binding matching FGFs (33). In colorectal cancer, FGFR2 is highly expressed and correlates with tumor growth, metastasis and angiogenesis (34). A reduction in FGFR2 expression was observed to inhibit proliferation of ovarian cancer cell lines in vitro and additionally reduced the half maximal inhibitory concentration of cisplatin (35). FGFR2 has been implicated in the regulation of apoptosis in several types of cancer. Overexpression of FGFR2 in breast cancer is correlated with a lower rate of apoptosis (36). Restoration of FGFR2 expression in human prostate cancer cell lines suppresses cell growth and tumorigenicity concurrent with increased cell differentiation and apoptosis (37). The results of the present study suggest that miR-494 induces apoptosis through targeting FGFR2.

In conclusion, the present study demonstrates that miR-494 is downregulated in ovarian cancer tissues. miR-494 may inhibit the proliferation of ovarian cancer cells by inducing apoptosis, potentially via targeting the anti-apoptotic gene FGFR2. The findings of the present study provide evidence for the clinical value of miR-494 as a target for ovarian cancer therapy, and the precise regulatory mechanisms underlying these findings are recommended for additional study in the future.

\section{References}

1. Farazi TA, Hoell JI, Morozov P and Tuschl T: MicroRNAs in human cancer. Adv Exp Med Biol 774: 1-20, 2013.

2. Friedman RC, Farh KK, Burge CB and Bartel DP: Most mammalian mRNAs are conserved targets of microRNAs. Genome Res 19: 92-105, 2009.
3. Shen W, Song M, Liu J, Qiu G, Li T, Hu Y and Liu H: MiR-26a promotes ovarian cancer proliferation and tumorigenesis. PLoS One 9: e86871, 2014.

4. Zhang H, Wang Q, Zhao Q and Di W: MiR-124 inhibits the migration and invasion of ovarian cancer cells by targeting SphK1. J Ovarian Res 6: 84, 2013.

5. Torre LA, Bray F, Siegel RL, Ferlay J, Lortet-Tieulent J and Jemal A: Global cancer statistics, 2012. CA Cancer J Clin 65: 87-108, 2015

6. Tung CS, Wong KK and Mok SC: Biomarker discovery in ovarian cancer. Womens Health (Lond Engl) 4: 27-40, 2008.

7. Chen D, Zhang Y, Wang J, Chen J, Yang C, Cai K, Wang X, Shi F and Dou J: MicroRNA-200c overexpression inhibits tumorigenicity and metastasis of CD117+CD44+ ovarian cancer stem cells by regulating epithelial-mesenchymal transition. J Ovarian Res 6: 50, 2013.

8. Wang Y, Kim S and Kim IM: Regulation of metastasis by microRNAs in ovarian cancer. Front Oncol 4: 143, 2014.

9. Song L, Liu D, Wang B, He J, Zhang S, Dai Z, Ma X and Wang X: miR-494 suppresses the progression of breast cancer in vitro by targeting CXCR4 through the Wnt/ $\beta$-catenin signaling pathway. Oncol Rep 34: 525-531, 2015.

10. Shen PF, Chen XQ, Liao YC, Chen N, Zhou Q, Wei Q, Li X, Wang J and Zeng H: MicroRNA-494-3p targets CXCR4 to suppress the proliferation, invasion, and migration of prostate cancer. Prostate 74: 756-767, 2014.

11. Kim WK, Park M, Kim YK, Tae YK, Yang HK, Lee JM and Kim H: MicroRNA-494 downregulates KIT and inhibits gastrointestinal stromal tumor cell proliferation. Clin Cancer Res 17: 7584-7594, 2011

12. Ohdaira H, Sekiguchi M, Miyata $K$ and Yoshida $K$ : MicroRNA-494 suppresses cell proliferation and induces senescence in A549 lung cancer cells. Cell Prolif 45: 32-38, 2012.

13. Asuthkar S, Velpula KK, Nalla AK, Gogineni VR, Gondi CS and Rao JS: Irradiation-induced angiogenesis is associated with an MMP-9-miR-494-syndecan-1 regulatory loop in medulloblastoma cells. Oncogene 33: 1922-1933, 2014.

14. Kwak SY, Yang JS, Kim BY, Bae IH and Han YH: Ionizing radiation-inducible miR-494 promotes glioma cell invasion through EGFR stabilization by targeting p190B rhoGAP. Biochim Biophys Acta 1843: 508-516, 2014.

15. Lim L, Balakrishnan A, Huskey N, Jones KD, Jodari M, Ng R, Song G, Riordan J, Anderton B, Cheung ST, et al: MicroRNA-494 within an oncogenic microRNA megacluster regulates G1/S transition in liver tumorigenesis through suppression of mutated in colorectal cancer. Hepatology 59: 202-215, 2014.

16. Livak and Schmittgen: Analysis of relative gene expression data using real-time quantitative PCR and the $2-\Delta \Delta \mathrm{Ct}$ method. Methods 25: 402-408, 2001.

17. Webb PM: Environmental (nongenetic) factors in gynecological cancers: Update and future perspectives. Future Oncol 11: 295-307, 2015.

18. Macfarlane LA and Murphy PR: MicroRNA: Biogenesis, function and role in cancer. Curr Genomics 11: 537-561, 2010.

19. Fabian MR, Sonenberg N and Filipowicz W: Regulation of mRNA translation and stability by microRNAs. Annu Rev Biochem 79: 351-379, 2010.

20. Bartels CL and Tsongalis GJ: MicroRNAs: Novel biomarkers for human cancer. Ann Biol Clin (Paris) 68: 263-272, 2010 (In French).

21. Yamanaka S, Campbell NR, An F, Kuo SC, Potter JJ, Mezey E, Maitra A and Selaru FM: Coordinated effects of microRNA-494 induce $\mathrm{G}_{2} / \mathrm{M}$ arrest in human cholangiocarcinoma. Cell Cycle 11: 2729-2738, 2012

22. Libório-Kimura TN, Jung HM and Chan EK: miR-494 represses HOXA10 expression and inhibits cell proliferation in oral cancer. Oral Oncol 51: 151-157, 2015.

23. Zhang R, Chen X, Zhang S, Zhang X, Li T, Liu Z, Wang J, Zang W, Wang Y, Du Y and Zhao G: Upregulation of miR-494 inhibits cell growth and invasion and induces cell apoptosis by targeting cleft lip and palate transmembrane 1-like in esophageal squamous cell carcinoma. Dig Dis Sci 60: 1247-1255, 2015.

24. He W, Li Y, Chen X, Lu L, Tang B, Wang Z, Pan Y, Cai S, $\mathrm{He} \mathrm{Y}$ and $\mathrm{Ke} \mathrm{Z}$ : miR-494 acts as an anti-oncogene in gastric carcinoma by targeting c-myc. J Gastroenterol Hepatol 29: 1427-1434, 2014.

25. Ries J, Vairaktaris E, Agaimy A, Kintopp R, Baran C, Neukam FW and Nkenke E: miR-186, miR-3651 and miR-494: Potential biomarkers for oral squamous cell carcinoma extracted from whole blood. Oncol Rep 31: 1429-1436, 2014. 
26. Duan H, Jiang Y, Zhang $\mathrm{H}$ and Wu Y: MiR-320 and miR-494 affect cell cycles of primary murine bronchial epithelial cells exposed to benzo[a]pyrene. Toxicol In Vitro 24: 928-935, 2010.

27. Kim YW, Kim EY, Jeon D, Liu JL, Kim HS, Choi JW and Ahn WS: Differential microRNA expression signatures and cell type-specific association with Taxol resistance in ovarian cancer cells. Drug Des Devel Ther 8: 293-314, 2014.

28. Yuan J, Wang K and Xi M: miR-494 inhibits epithelial ovarian cancer growth by targeting c-Myc. Med Sci Monit 22: 617-624, 2016.

29. Li XT, Wang HZ, Wu ZW, Yang TQ, Zhao ZH, Chen GL, Xie XS, Li B, Wei YX, Huang YL, et al: miR-494-3p Regulates Cellular proliferation, invasion, migration, and apoptosis by PTEN/AKT signaling in human glioblastoma cells. Cell Mol Neurobiol 35: 679-687, 2015

30. Romano G, Acunzo M, Garofalo M, Di Leva G, Cascione L, Zanca C, Bolon B, Condorelli G and Croce CM: MiR-494 is regulated by ERK1/2 and modulates TRAIL-induced apoptosis in non-small-cell lung cancer through BIM down-regulation. Proc Natl Acad Sci USA 109: 16570-16575, 2012.

31. Wang X, Zhang X, Ren XP, Chen J, Liu H, Yang J, Medvedovic M, $\mathrm{Hu} \mathrm{Z}$ and Fan GC: MicroRNA-494 targeting both proapoptotic and antiapoptotic proteins protects against ischemia/reperfusion-induced cardiac injury. Circulation 122: 1308-1318, 2010.
32. Amann T, Bataille F, Spruss T, Dettmer K, Wild P, Liedtke C, Mühlbauer M, Kiefer P, Oefner PJ, Trautwein C, et al: Reduced expression of fibroblast growth factor receptor $2 \mathrm{IIIb}$ in hepatocellular carcinoma induces a more aggressive growth. Am J Pathol 176: 1433-1442, 2010.

33. Liang J, Chen P, Hu Z, Zhou X, Chen L, Li M, Wang Y, Tang J, Wang $\mathrm{H}$ and Shen $\mathrm{H}$ : Genetic variants in fibroblast growth factor receptor 2 (FGFR2) contribute to susceptibility of breast cancer in Chinese women. Carcinogenesis 29: 2341-2346, 2008.

34. Matsuda Y, Ueda J and Ishiwata T: Fibroblast growth factor receptor 2: Expression, roles, and potential as a novel molecular target for colorectal cancer. Patholog Res Int 2012: 574768, 2012.

35. Cole C, Lau S, Backen A, Clamp A, Rushton G, Dive C, Hodgkinson C, McVey R, Kitchener H and Jayson GC: Inhibition of FGFR2 and FGFR1 increases cisplatin sensitivity in ovarian cancer. Cancer Biol Ther 10: 495-504, 2010.

36. Tannheimer SL, Rehemtulla A and Ethier SP: Characterization of fibroblast growth factor receptor 2 overexpression in the human breast cancer cell line SUM-52PE. Breast Cancer Res 2: 311-320, 2000.

37. Yasumoto $\mathrm{H}$, Matsubara A, Mutaguchi $\mathrm{K}$, Usui $\mathrm{T}$ and McKeehan WL: Restoration of fibroblast growth factor receptor2 suppresses growth and tumorigenicity of malignant human prostate carcinoma PC-3 cells. Prostate 61: 236-242, 2004. 